\title{
Sentinel-1 Satellite Data as a Tool for Monitoring Inundation Areas near Urban Areas in the Mexican Tropical Wet
}

\author{
Alejandra A. López-Caloca, \\ Felipe Omar Tapia-Silva and Guadalupe Rivera
}

Additional information is available at the end of the chapter

http://dx.doi.org/10.5772/intechopen.71395

\begin{abstract}
This work shows advances in the field of water body monitoring with radar images. Particularly, a monitoring procedure is developed to define the extension and frequency of inundation for continental waters of the Grijalva-Usumacinta basin, in the state of Tabasco, Mexico. This is a region located in the Mexican tropical wet and under its meteorological conditions, radar technology can be used to characterize monthly inundation frequency. The identification of water bodies were obtained by processing images at a monthly intervals captured by Sentinel-1A during 2015 having kappa indices and overall accuracy higher than 0.9. The chapter describes the seasonal variability of these water bodies, and at the same time, the relationship with human settlements located in their neighborhood. To do this, a proximity analysis was carried out to emphasize the importance of spatialtemporal studies of superficial water bodies, linked to an urban and a rural area. This information is useful to investigate changes in the ecosystem, as well as risks to human settlements, and as a contribution for a comprehensive management of hydric resources.
\end{abstract}

Keywords: Sentinel 1A, water body, urban areas, Tabasco, Mexico

\section{Introduction}

The location and evolution of cities are defined by the geographic spaces where they are established, so that they generate well-being for their inhabitants through services such as: drinking water, food, power, transportation, recreation, among other services [1]. The dynamics of urban growth over time modify the spatial form and organization of the urban space, as well as of the 
surrounding natural and rural areas. Different authors agree that urbanization presents problems pertaining to water demand, land-and land cover changes [2, 3], irregular human settlements, pollution, and the production of wastewater [4]. Thus, rapid urbanization on the land's surface leads to the ecological instability of natural resources, compromising and overwhelming their capacity for providing environmental services. The consequences of exceeding the capacity of natural resources are the degradation, fragility, and loss of biodiversity, due to an increase in the demand for natural resources. At the same time, climate change problems arise.

Historically, the foundation and development of urban spaces has had a direct relationship to the closeness of natural sources of drinking water, since many important cities are located at the edges of great lakes, or along the coast and rivers. To date, research on the impact of urbanization on lakes and rivers, includes works documented at the urban ecology, urban catchments, and landscape ecology levels [5-7]. Several cities have had an impact on hydric resources, modifying the course of rivers and their connection with the stream that feeds them. To increase the urban land area, the expansion has led to the implementation of drainage processes, drying out, and the losing of surface water bodies. The elimination of vegetation changes the permeability of soils, impermeable soils increase runoff and the accumulation of water increases when a suitable drainage network is not available.

To understand the conservation and loss of water body surfaces, Dunne [8] proposed an evaluation of how cities create changes in land-use and their effects on hydrography. Yue [9] suggests investigating urban rivers by considering fundamental themes such as the characterization of the hydrological pattern and function. In the U.S. National Context, the study by Steele and Heffernan [10], related the patterns and characteristics pertaining to shape, form and connectivity of surface water and urban spaces in 100 U.S. cities. Based on their location and attributes, water bodies on urban land covers tend to reduce their size, and in the urban space there are also fewer water bodies connected to streams and rivers, compared to nonurbanized lands. Small water bodies are mostly affected by urbanization.

The study of seasonal patterns of water bodies is an indicator of the natural behavior of water and helps society in decision-making with respect to water management, providing more information on when and how the natural protected areas must be established and for building basic infrastructure (dams, dikes, and bridges). This will allow for a decrease in possible losses due to flooding, in terms of life, property, and businesses. An example of one study regarding the importance of water body monitoring in Tabasco, México is found in the work by Rodríguez [11], who make an inventory of continental lagoons in Tabasco, in the year 2002. The study shows the importance of the information on surface water areas and their water body morphological analysis, applied to a model of fishing efficiency.

In view of this situation, we need to explore more sustainable alternatives in terms of the relationship between surface waters and metropolitan areas [12], with a focus on Integrated Water Resources Management (IWRM). This is defined as "a process that promotes the coordinated development and management of hydric, land and other resources, in order to achieve maximum economic and social well-being in an equitable manner, without compromising the sustainability of vital ecosystems" GWP [13]. Savenije and Van der Zaag [14] described four key factors in IWRM, which are: the water resources, the water users, the spatial scale, and the temporal scale. The first two refer to the natural behavior of water, to human aspects and requirements, 
while the third key factor points to the spatial geographic distribution and the hydrology of water bodies. Some regions and countries such as Africa [15], Holland, and Great Britain have broad knowledge and experience with geographic space, water management, and logistics, to face problems pertaining to excess water due to precipitation or drought. The last key factor refers to the behavior and temporal variability of water, as well as to its demand, a factor affected by drought or flooding. The consequences of surface water redistribution at spatial and temporal scales, including the landscape level, are not well known. Steele and Heffernan [10] found that cities gain or lose water, so that they become different from their surrounding natural landscapes, in terms of the spatial configuration. There is a lack of studies to investigating the spatial and temporal variability of water bodies and their effects on urban areas.

The objective of this investigation is to contribute to the analysis of this process, based on the study of the inter-relationships between water dynamics in lakes and rivers and urban space in a part of the Mexican tropical wet. The chapter analyzes the dynamics of surface water bodies in the low plains of South-Eastern Mexico. The urbanization process that happened in the low lands of the region and in the flatlands, far from being a planned growth, obeyed economic needs and the need for land for housing. Because of their geographic location, the dynamics of these territories involve frequent flooding area changes in relatively short times because of the high volume observed during the rainy months.

In this sense, a monthly spatial-temporal analysis is set forth, of water bodies that are linked to rural and urban zones of Villahermosa, in the state of Tabasco. The research strategy uses satellite images, since these are powerful tools to identify the geographic features, such as places and natural aspects. These new satellite technologies facilitate processing and extraction of information for consistent, multi-temporal measurements of water body surfaces. Through the processing of Sentinel 1A radar images, the spatial and temporal variability of the water bodies' footprint was defined. The radar data allow us to have a closer look at seasonality, size, hydrological connectivity, and water storage capacity of the water bodies. They are relevant indicators for the study of eco-hydrological regions with the presence of water bodies near urban spaces. From this perspective, we see the relevance of establishing a monitoring system based on Sentinel satellite data. The satellite data reveal the spatial patterns of water bodies and may be used for the evaluation and monitoring of hydric resources at the spatial and temporal scales that are adequate for urban spaces. The relationship of the water bodies with an urban area and a rural one is studied through an analysis of proximity. The population living in these areas prone to flooding was located. Due to frequent inundation, this kind of tropical zones needs to be prepared to face possible flooding and public health problems related to infectious diseases that are mainly transmitted by mosquitoes that reproduce during the rainy season.

\section{Case study: state of Tabasco, Mexico}

\subsection{Study area}

The area of study is located in the low Grijalva-Usumacinta eco-hydrological region, which was defined by the Freshwater Ecoregions of the World Map (FEOW) [16]. The FEOW defines a freshwater ecoregion as "A large area encompassing one or more freshwater systems that contains a 
distinct assemblage of natural freshwater communities and species". The Grijalva-Usumacinta ecoregion located in Tabasco México, as reported by FEOW, covers a surface of 112,008 Km². Figure 1 shows the delimitation of the study area, based on FEOW. The freshwater ecoregion is coherent with the country's hydrological zones, according to works carried out by the Conagua [17]. The water body systems studied in this chapter are included in the three most important hydrological systems of the country. Conagua [17] reports an average annual precipitation of $1709 \mathrm{~mm}$ for the Grijalva-Usumacinta hydrological region, during the years 1971-2000. The region has a mean natural total superficial runoff of $117,396\left(\mathrm{hm}^{3} /\right.$ year $)$, defined by its 87 hydrological basins.

The Grijalva River flows through the city of Villahermosa, and through the state of Chiapas and small parts of the state of Campeche. The Grijalva River flows into the Usumacinta River; both rivers form the swampy delta called Pantanos de Centla, which flows into the Gulf of Mexico. The Laguna de las Ilusiones and Laguna del Negro are inner lagoons located in the city of Villahermosa.

The city of Villahermosa, as well as the hydrological systems to which it belongs, forms a large plain of fluvial origin. Normally, it is a water circulation zone. During the dry season (with precipitation $<100 \mathrm{~mm}$ ) in the period from February to April, according to SMN [18], the drastic seasonal descent of water bodies decreases food and vegetation that are vital for many species. During the intense rainy season (July to October), hurricanes and cold fronts occurring in the study area, frequently lead to flooding and landslides on highways causing

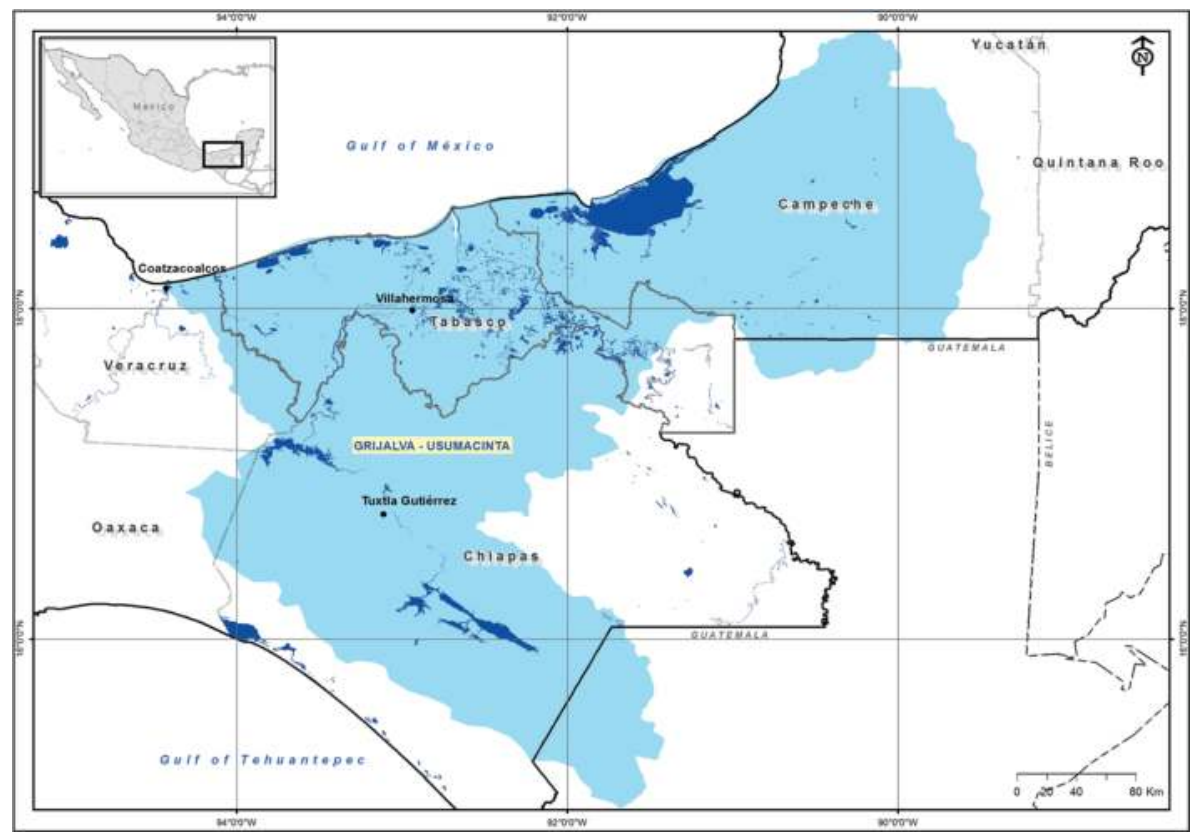

Figure 1. Map of hydrological ecoregions of the FEOW, Grijalva-Usumacinta region, in blue. The map also shows the limits of the state of Tabasco. 
disasters, and leaving the populations centers isolated and without communication [19]. This is documented in historical records of flooding and atypical rainy seasons. For the state of Tabasco, the Dartmouth Flood Observatory (DFO) reports events with damages to the population during the months of October to December (October 10-17, 2000; October 12-28, 1999, and October 28, 2007-December 1, 2007). Gama et al. [19] point out that during the 2006-2010 period, the Grijalva-Usumacinta watershed had six extreme events with flooding, generating risk for the population. They also include a risk map for the whole state.

Two economic regions are identified in the state of Tabasco: the Grijalva and the Usumacinta regions. The Grijalva region is subdivided into the Chontalpa, Centro, and Sierra economic subregions, and the Usumacinta region is subdivided into the Ríos and Pantanos subregions. The Grijalva region is the most populated one in the state, with the greatest industrial and commercial growth. Here we find the most important urban centers, such as the city of Villahermosa. Loss of natural ecosystems as a result of human activities can be observed. The rural and urban localities of the Grijalva region in Tabasco have undergone rapid population growth. Urban expansion has taken place without planning processes. As a result, the population's quality of life has been affected by drought during the dry season and by high precipitation during the rainy season. Also, the inhabitants now suffer from water shortage in a region that is normally considered to have high water availability.

Figure 2 shows a map including the urban limits of the city of Villahermosa and its metropolitan area, located in the Centro municipality. In this map, the urban area of the years 2000, 2005, 2010, and 2015, as defined by the National Institute of Statistics and Geography (INEGI, Spanish acronym, Mexico) land cover data, are compared. In this 15 year period, the urban area increased by $14 \mathrm{~km}^{2}$.

\subsection{Methodology}

\subsubsection{SAR signal and water surfaces}

Recent research has shown the feasibility of Synthetic Aperture Radar (SAR) images, as a source of information on water surface. The advantage of SAR images is that they provide useful data regardless of the weather conditions (can penetrate clouds, rain, and smoke) and lighting conditions. The radar signal is a relationship between the energy transmitted by the sensor's microwaves to the Earth and the reflected energy, that is, the return signal to the sensor. The energy or signal that returns to the sensor is called backscattering [20]. The acquisition parameters and the characteristics of the water surfaces affect the radar return signal. According to Lewis [21], the parameters affecting radar backscatter are the following: roughness, dielectric constant, incidence angle, and wavelength.

Many water bodies are related to wetlands and aquatic vegetation living submerged or partly submerged, or with leaves that float on the surface. Lewis [21] says the following about the radar response: "Corner reflection or Dihedral reflection often is observed from the combination of trees beside a specularly reflecting surface." In this case, the signal is enhanced and there is a double bounce effect between the trunks and water, which send most of the transmitted signal to the SAR antenna and which increases the water contrast, resulting in bright tones on SAR images [22]. 


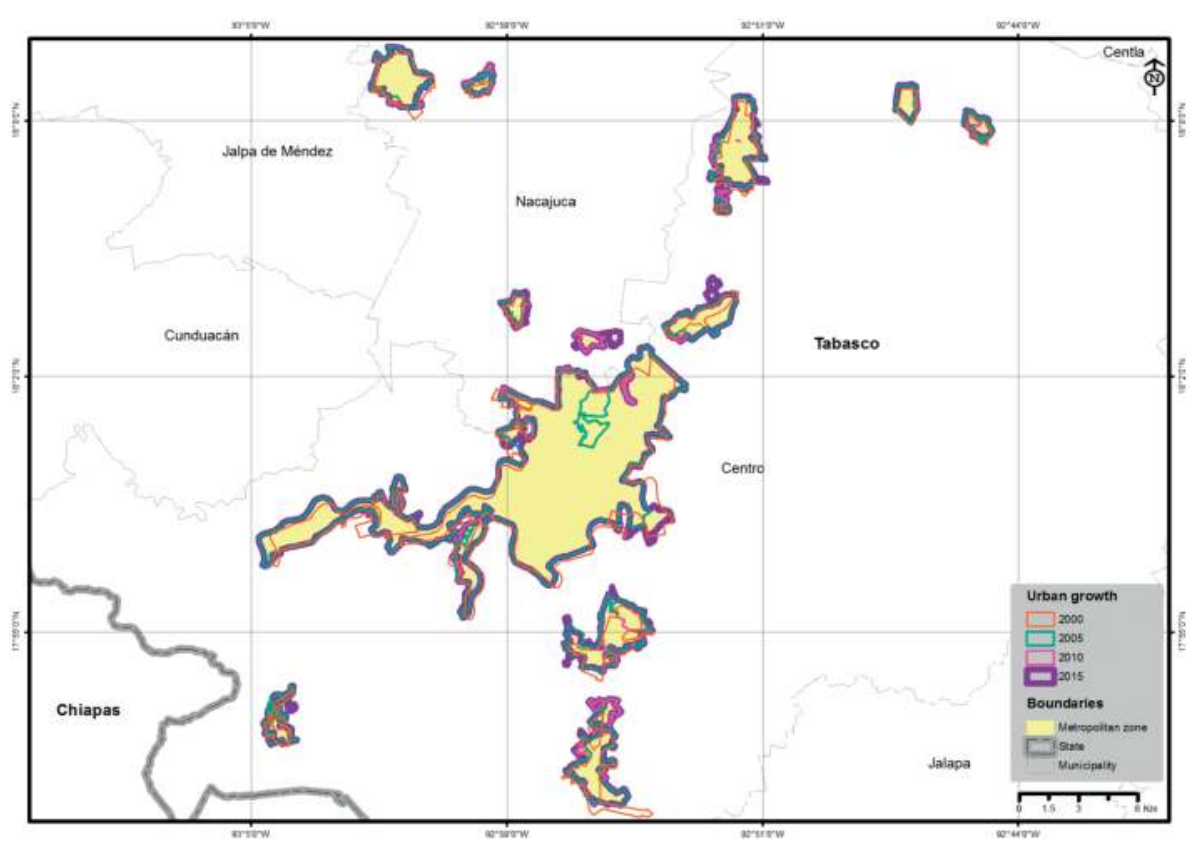

Figure 2. Regional context. Urban growth map showing urban limits and comparing the following years: 2000, 2005, 2010, and 2015, considering the area of the Villahermosa metropolitan zone in the Grijalva basin. Source: INEGI cartography and land cover data.

The backscattering coefficient term, $\sigma^{0}$, is a physical quantity. This coefficient is highly dynamic and is usually expressed in decibels $(\mathrm{dB})$. Some refer to it as sigma naught, or sigma zero. Backscattering coefficients provide information on the observed surface, with values ranging from $+5 \mathrm{~dB}$ for very bright objects to $-40 \mathrm{~dB}$ for very dark surfaces. The surface of a water body is detectable in radar images. The backscattering coefficient of water, using Sentinel $1 \mathrm{~A}$ data with VV polarizations, varies from -6 to $-15 \mathrm{~dB}$, and for $\mathrm{VH}$ polarizations, it varies from -15 to $-24 \mathrm{~dB}[23]$.

When a lake is calm, the behavior with respect to the radar signal is called specular reflector, which means that the incident radar signal reaching the lake reflects almost all the incident energy far from the sensor. Plain surfaces like water bodies appear in dark tones in the radar image, since the antenna does not receive a strong signal. The contrast of the dark tone makes an ideal separation possible, between the water cover and the land.

When the surfaces of a lake or river have emerging vegetation and movement due to wind, rain, and vegetation, the result is that superficial layers of the water body show superficial roughness and thus, it is difficult to have contrast between the tones of the land-water covers. In terms of values of the backscattering coefficient, this means that the roughness of the water's surface results in a high signal return and the separation of the land-water covers is made more difficult because of the decrease in the contrast. 
Besides, we must consider that water and land separation may be problematic if there are types of covers that may present the specular reflection effect, such as smooth surfaces (airport runways, streets, or plain bare ground), radar shadows, very dry ground (sand), and open sand dunes which appear in dark tones resulting in low backscatter returns under $-20 \mathrm{~dB}$ [21].

The relationship between backscatter and local incidence angle is also very important to distinguish between surface conditions [23, 24]. The geometric effects are due to the terrain's relief; when the incidence angles are large, they tend to have radar shadowing effects, and on the contrary, small incidence angles favor layover effects. To decrease the effects of shadowed areas, images have been recorded at different vision angles or directions of the orbit's trajectory (ascending or descending), as reported by Chunxi et al. [25]. O'Grady et al. [26] tried to mitigate the problems related to wind effects, comparing the SAR response and using the difference between the incidence angle of the radar signal and backscattering over land and water; also, the way in which radar backscattering varies with the incidence angle may be used to differentiate the land-water separation.

Among the works using X-and C-band wavelengths to produce water surface maps, we highlight the ones referred by Bolanos et al. [27] and Brisco et al. [28, 29], with Radarsat-1 and 2 (C-band) data, Martinis and Twele [30] and Gstaiger et al. [31] with Terrasar-X (X-band) data, and Twele et al. [32], Cazals et al. [33], Muro et al. [34], and Yésou et al. [35] using Sentinel 1.

$\mathrm{HH}$ polarization is preferred for cartography of flooded vegetation and water classification, since it maximizes canopy penetration and increases the contrast between water and its surroundings [28, 29]. Besides, $\mathrm{HH}$ has less backscatter on rough water surface (roughness induced by wind), than $\mathrm{VV}$, and is thus better for windy conditions.

The Sentinel-1 scene offers the potential to obtain data to describe the temporal and seasonal variations in water bodies' extension. Sentinel-1A C-band usually acquires data on VV/VH polarization over the Earth's land cover. Twele et al. [32] analyzed the polarization behavior with Sentinel data; the VV band shows a higher signal response in double bounce conditions than $\mathrm{VH}$, but $\mathrm{VH}$ polarization shows higher backscatter variability on land surfaces. In terms of thematic accuracy, VV polarization is slightly higher than that of $\mathrm{VH}$ polarization.

\subsubsection{Available Sentinel data 1}

Sentinel-1A [36] carries a synthetic aperture radar (SAR) and produces, since the end of 2014, images that cover the same scene in a 12 day cycle, with a mean resolution of $20 \mathrm{~m}$. The data acquisition frequency of Sentinel-1 satellites for the same geographic scene offers the potential to obtain data on the temporal and seasonal variations in the behavior of water bodies. The SAR data were obtained from the server of the Copernicus Open Access Hub. The total number of images was 36 (track 172, 99, and 26), and they were obtained between January and December 2015.

Reference Data. To determine the training sites and the validation of estimates of the water body extraction G3WBM and INEGI water body data (2015) were used. Global 3-second Water Body Map (G3WBM) (November 2015) [37] is a global scale high-resolution water body 
map obtained using multi-temporal Landsat data. This cartography shows the water body distribution at a global level, with a spatial resolution of $90 \mathrm{~m}$.

\subsubsection{Workflow of water body extraction}

The analysis of data from the Sentinel 1A temporal series is based on a processing chain shown in Figure 3. First, corrections were carried out in a pre-processing phase. Based on these images, water body extraction was performed with a supervised classification method, using the Support Vector Machine algorithm to obtain the binary mask of the lakes, lagoons, and rivers. The validation of the obtained results was done comparing the areas of certain selected lakes with the reference data to obtain confusion matrices and overall accuracy and Kappa indexes. Finally, estimates of water frequency were based on the average monthly mean of water presence/absence. The software that was used was: (1) SNAP for pre-processing, (2) Monteverdi, for water mask extraction, and (3) gvSIG, Quantum GIS; besides, for cartographic representation of results, Quantum GIS was used for post-classification.

\subsubsection{Data pre-processing}

The Orbit State Vector in the metadata file of Sentinel C band product is a file that includes the general acquisition parameters. To ensure that the file of the precise orbit information is updated, the precise orbit ephemerides (POD) file is provided and located by the Sentinel-1 payload data ground segment (PDGS). Thermal noise removal (TNR) is used to remove noise before performing calibration. This step is needed to eliminate those values that are seriously affected by this type of noise.

The purpose of the Radiometric Calibration is to convert the digital level values to backscattering coefficient values. The SAR calibration methods proposed by Freeman [20] allow us

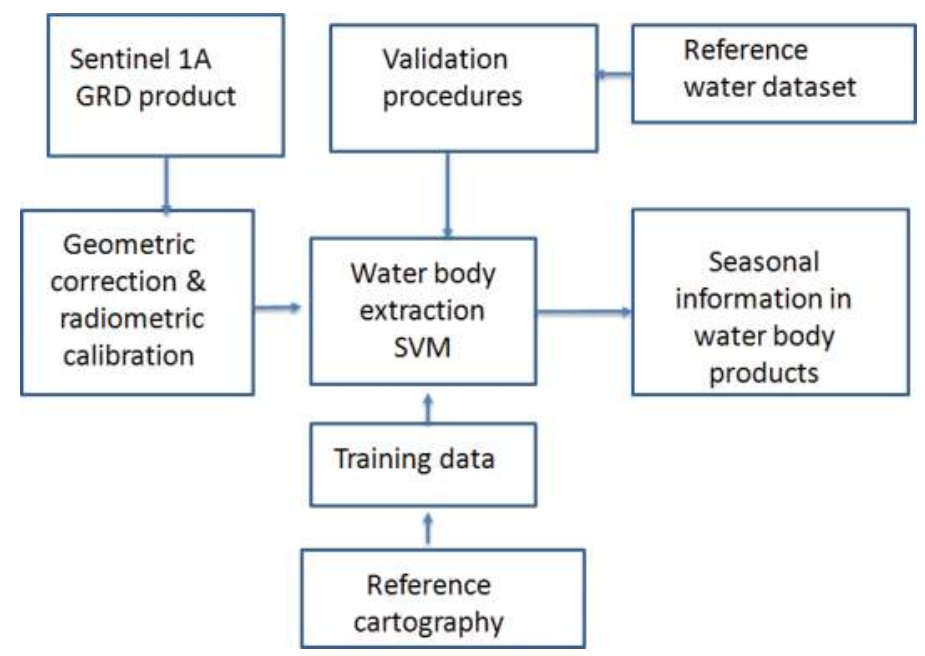

Figure 3. Study methodological scheme. 
to convert radar reflectivity to physical units; these depend on the characteristic SAR system, ERS or Sentinel-1. The calibration equation of the Sentinel products follows the generic ENVISA-ASAR expression. According to the Sentinel-1 (S-1) Instrument Processing Facility (IPF) document [38], the equation of the $\sigma^{0}$ radar cross-section is simplified to: $\sigma^{0}=\mathrm{DN}^{2} /$ $\left(\mathrm{A}_{\mathrm{dn}}^{2} \mathrm{k}\right)^{*} \sin (\alpha)$, where $\mathrm{DN}$ is the pixel Digital Number, $\mathrm{k}$ is the calibration constant, and $\mathrm{A}_{\mathrm{dn}}$ is the product final scaling from GRD $\left(\mathrm{A}_{\mathrm{dn}}\right.$ is an area normalization factor and $\alpha$ is the incident angle). For GRD products a constant offset is also applied by the following simplified equation: $\sigma^{0}=\mathrm{DN}^{2} / \mathrm{A}_{\sigma^{\prime}}{ }$, where $\sigma^{0}$ is the backscattering coefficient and $\mathrm{A}_{\sigma}$ is used to transform the radar reflectivity into radar cross-section $\sigma^{0}$. The $\sigma^{0}$ values can be transformed to $\mathrm{dB}$ values considering the following formula: $\sigma_{\mathrm{db}}^{0}=10 \log _{10} \sigma^{0}$.

The multi-look refers to the divisions of the total aperture, which is subdivided into several sub-apertures. With each sub-aperture, an image is formed. All images are averaged. The typical number of looks is $1-4$. Each sub-aperture gives an independent look to the illuminated scene. Each one of these looks will be subjected to speckle, but by the sum and average of resolution cells, all together they will form the resulting radar image with a reduced speckle. The multi-look process is done during data acquisition. The average can be obtained in the frequency domain by averaging images of individual frequency parts in range and/or azimuth; or in the spatial (time) domain by averaging individual resolution cells in range and/ or azimuth [39]. The multi-look process allows for the creation of squared pixels.

In general, all radar images show a degree of speckle that is manifested as a salt and pepper granular pattern. Actually, speckle is a form of noise that degrades the quality of an image and can make visual interpretation more difficult. Noise in SAR images has a structure that is different from other image processing systems. The ideal filter used to reduce speckle is the one that does not lose any information. For example, in the homogenous areas, the filter must preserve the radiometric information, as well as preserve the edges of the different areas in the textured zones. In practice, Lee Sigma Filter was used to filter speckle. Finally, Geometric Terrain Correction was performed. The main geometric distortions are: (1) layover, (2) shadowing, and (3) foreshortening. The algorithm uses a Digital Elevation Model SRTM 3-arc-second to make the correction. The resulting corrected image remains in its correct geographic orientation. The final coordinates are geographical WGS84.

\subsubsection{Surface water extraction}

To date, automated algorithms have been developed for pattern recognition, detection, delineation, and segmentation of water bodies. This progress entails pre-processing of images, obtaining backscattering coefficients, and tackling problems related to body delineation caused by shadows, wind, aquatic vegetation, humidity gradients, and sediments, as previously mentioned.

There are many studies that have been done using radar satellite images to detect surface water. The method that is most broadly reported in the literature is the intensity thresholding method applied to the SAR image. In this method, water is separated from land in the intensity images, but the accuracy of the results is based on the ability to differentiate the land pixels vs. water in the intensity domain. There are several modifications to the thresholding 
method: [29, 32, 35, 40-44]. There are also different ways to improve the thresholding method. As an example, Cazals et al. [33] use a hysteresis thresholding algorithm which is complemented with data from in situ piezometric measurements combined with a Digital Terrain Model derived from LiDAR data.

With respect to the detection of changes and segmentation algorithms to determine the pixels belonging to water, we refer to Gstaiger [31], Kuenzer [45], Matgen [46], and Muro [34]. There are other methods such as split-based automatic thresholding and classification refinement and the hybrid context-based model, combining causal with non-causal Markov image modeling on irregular hierarchical graphs, applied by Martinis [30, 47], respectively. Twele [32] uses a fuzzy-logic-based classification refinement, with Sentinel-1 ground range detected (GRD) data. Lopez-Caloca et al. [48] used Sentinel-1 (GRD) data to classify the Support Vector Machine method (SVM).

We chose the SVM method to classify the set of monthly images. Post-classification was carried out by means of the filter with QGIS tools, to eliminate unclassified points, decrease the granular effect, and eliminate loose pixels of both classes. To make the database more coherent, each water layer was examined by visual interpretation.

\subsubsection{Validation}

To obtain an estimate of the error related to classifications. The results were compared based on the Kappa index. The comparison study of the area was performed for 2015 with the G3WBM and INEGI database information sources. The results of the water body binary masks obtained from the ascending mode were re-scaled to a spatial resolution of the $90 \mathrm{~m}$ reference product. To carry out the validation process, the classes from the compared images were homogenized in the following categories: permanent water bodies, flood areas, and other classes. Our results were considered as permanent water for pixels with frequency higher than $73 \%$.

\subsubsection{Frequency indicator}

The performed dynamic study is based on the work of Andreoli [43], and the determination of the frequency indicator. The frequency time $\mathrm{P}_{\mathrm{y}}(\mathrm{w})$ is an average of the monthly mean of water surfaces $\mathrm{P}_{\mathrm{y}, \mathrm{m}}(\mathrm{w})$ expressed in percent of year (Eq. (1))

$$
P_{y, m}(w)=\left(\frac{1}{N_{y, m}} \sum_{t=1}^{N_{y, m}} w_{y, m, t}\right) x 100
$$

where $\mathrm{m}$ is the month of the year, $\mathrm{y}$ is the year, $\mathrm{N}_{\mathrm{y}^{\prime} \mathrm{m}}$ is the number of water extent layers of the month $(\mathrm{m})$ of the year $(\mathrm{y})$ number of pixels identified as water $\left(\mathrm{N}_{\mathrm{y}^{\prime} \mathrm{m}}=12\right), \mathrm{w}_{\mathrm{y}, \mathrm{m}, \mathrm{t}}$ is the pixel value of the water extent layer extracted from Sentinel data for the month $(\mathrm{m})$ of the year $(\mathrm{y})$; with $t \in\left[1 ; n_{m}\right]$ and $w_{(m, t)} \in\{0,1\}$, and $t$ is the resolution of the data.

\subsubsection{Results}

The inundation frequency map is shown in Figure 4. Tables 1 and 2 present the results from the validation of the classifications based on confusion matrices and the kappa index. As can be seen, 


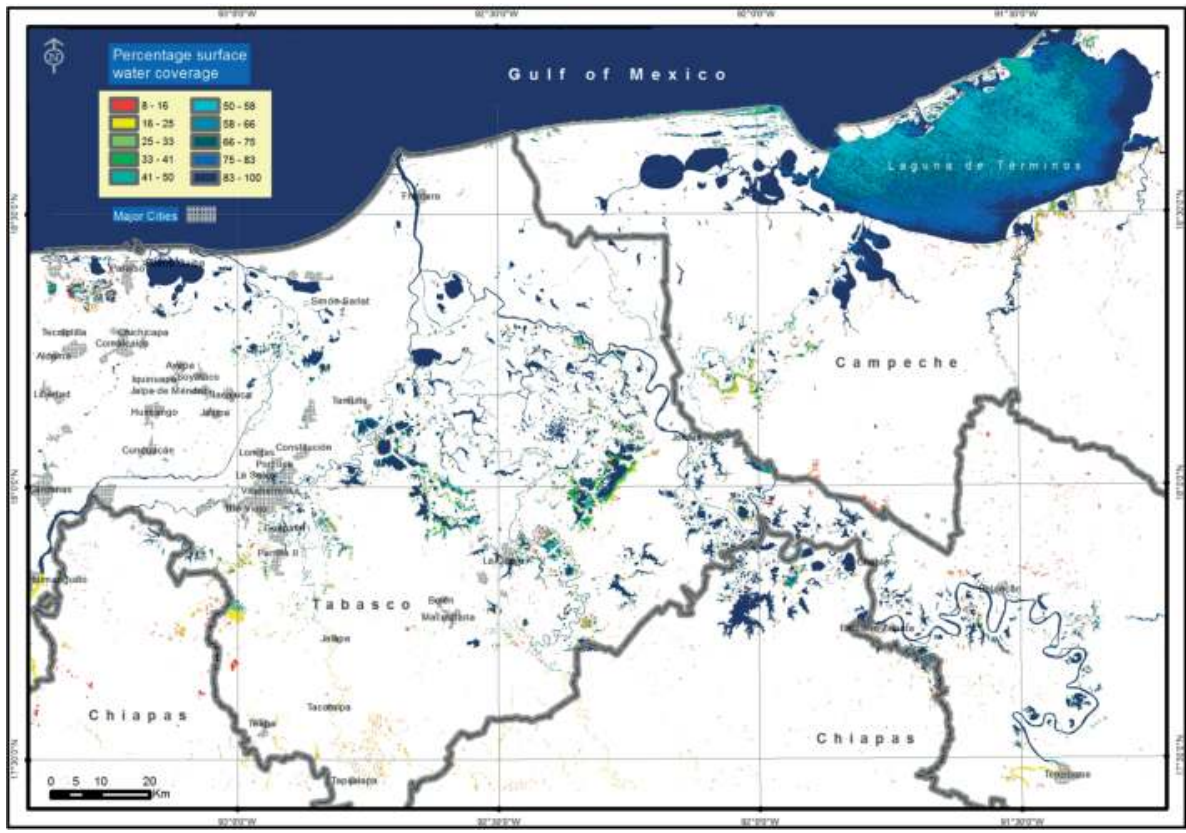

Figure 4. Inundation frequency map for 2015, the map including cities of interest in the state of Tabasco.

\begin{tabular}{cllllll}
\hline \multicolumn{2}{c}{ Reference data } & & & \\
\cline { 3 - 7 } & & Non-water & Water & Totals & $\begin{array}{l}\text { Commission error } \\
\mathbf{( \% )}\end{array}$ & $\begin{array}{l}\text { Estimated } \\
\text { kappa }\end{array}$ \\
\hline Predicted class & Non-water & 172,937 & 12,875 & 185,812 & 6.9 & 0.88 \\
& Water & 2416 & 229,618 & 232,034 & 1.0 & 0.97 \\
& Totals & 175,353 & 242,493 & 417,846 & & \\
& $\begin{array}{l}\text { Omission } \\
\text { error (\%) }\end{array}$ & 1.4 & 5.3 & & & \\
\hline
\end{tabular}

Table 1. Confusion matrix of the water/non-water classification using Sentinel radar data (March 2015) and adjusted INEGI's 2015 land cover data as reference data.

the kappa was in all cases very high, 0.92 for the comparison against INEGI data, and 0.97 for the comparison against G3WBM water body maps. The results show that it is feasible to use the water body extraction method with the SVM algorithm to monitor the whole state of Tabasco.

In global numbers for Tabasco state, the water body surface obtained from Yamazaki, based on the G3WBM product, is 1,531,429.40 $\mathrm{km}^{2}$, which is slightly lower than the number obtained from this study's map, which is $1,620,868.01 \mathrm{~km}^{2}$. Figure 4 shows a map with the inundation frequency by pixel, obtained by monthly binary masks of 2015. The dark blue color shows permanent water bodies and the red areas show the increase in water due to flooding. 


\begin{tabular}{lllllll}
\hline & \multicolumn{2}{c}{ Reference data } & & & \\
\cline { 3 - 7 } & & Non-water & Water & Totals & $\begin{array}{l}\text { Commission } \\
\text { error (\%) }\end{array}$ & $\begin{array}{l}\text { Estimated } \\
\text { kappa }\end{array}$ \\
\hline Predicted class & Non-water & $292,013,286$ & $3,230,447$ & $295,243,733$ & 1.1 & 0.97 \\
& Water & $5,943,121$ & $301,431,080$ & $307,374,201$ & 1.9 & 0.96 \\
& Totals & $297,956,407$ & $304,661,527$ & $602,617,934$ & & \\
& $\begin{array}{l}\text { Omission error } \\
(\%)\end{array}$ & 1.9 & 1.06 & & & \\
\hline
\end{tabular}

Overall accuracy: 98.47\%, Kappa Statistic (standard): 0.97.

Table 2. Confusion matrix of the water/non-water classification using Sentinel radar data (March 2015) and G3WBM version 1.2 water body maps as reference data.

Figure 5 shows a close-up of the extension of water bodies during 2015, over the Villahermosa metropolitan area. In the maps, permanent water cover is represented by blue and the nonpermanent water cover by red. To visualize the proximity of urban and rural centers, the administrative delimitation of these areas with human settlements is included. There, we may see the natural expansive process of the water bodies during the study year.

To complete the analysis, we carried out analysis of areas of influence based on distance to urban centers, calculating buffers using the Euclidian distance algorithm. Figure 6 shows the

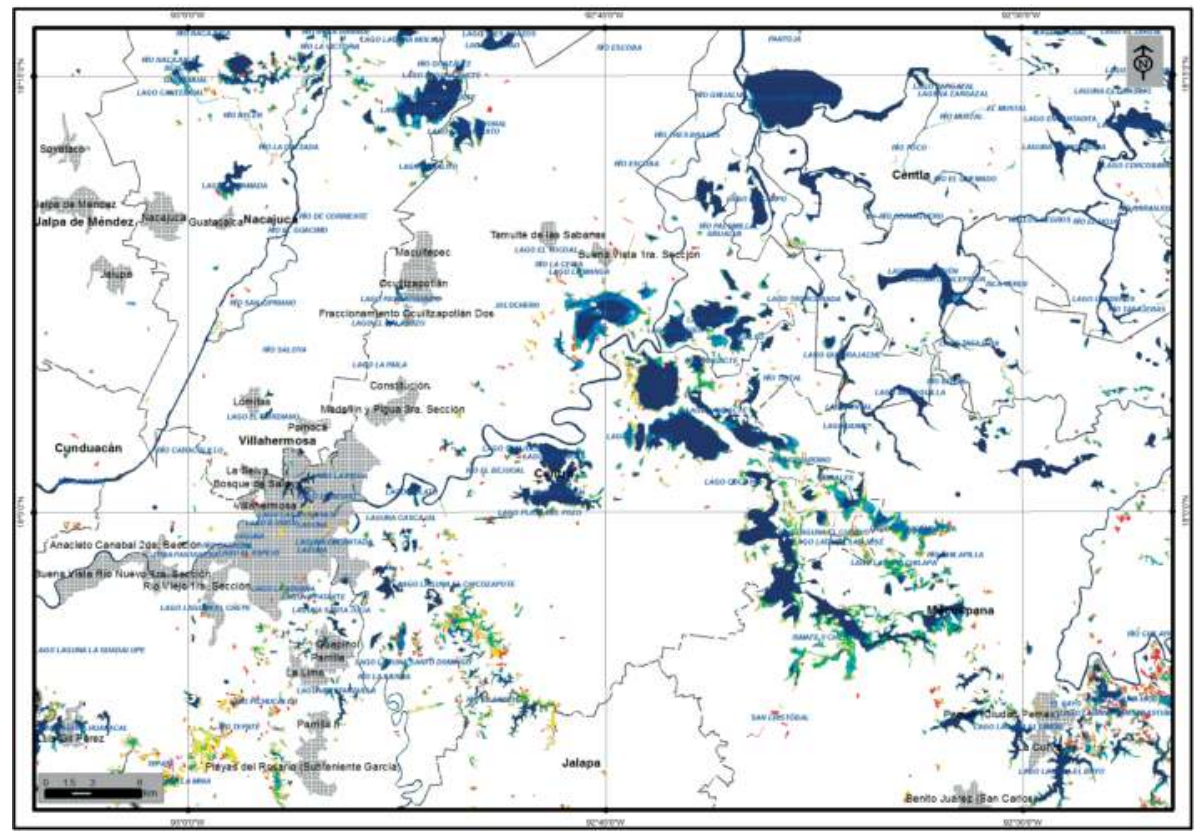

Figure 5. Villahermosa metropolitan area in the Centro municipality. 


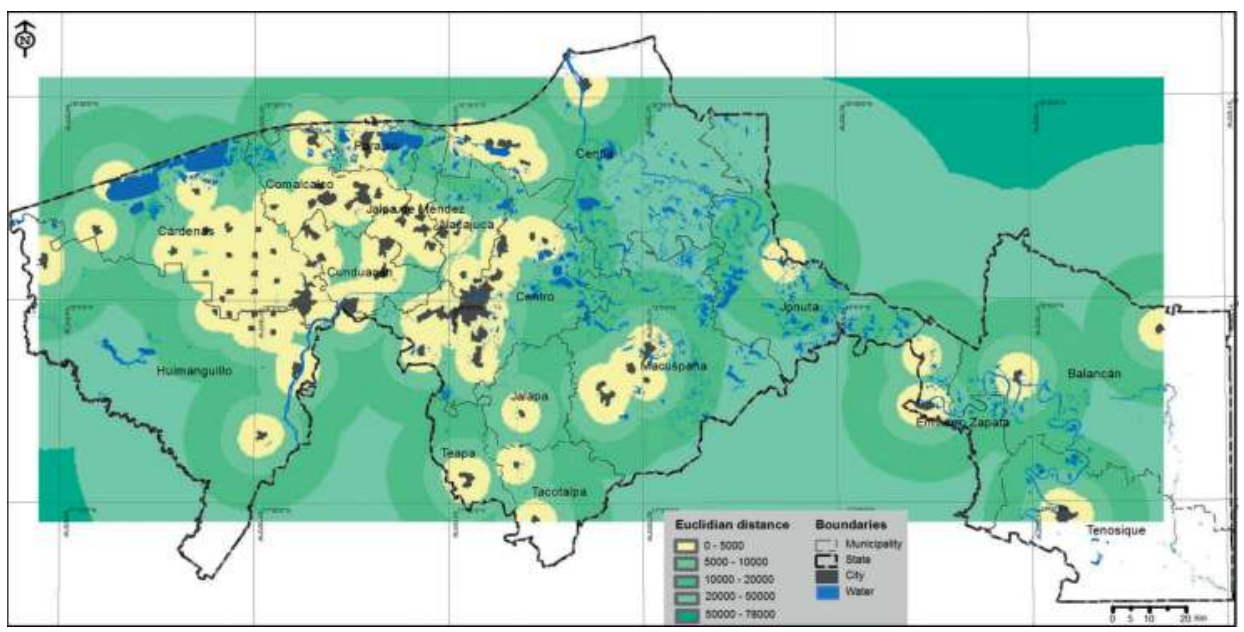

Figure 6. Map of urban and rural centers and areas of influence (buffers) of water bodies to $5000 \mathrm{~m}$, detected by the Sentinel-1A in 2015. The map shows the binary mask of the water bodies.

location of the urban and rural centers on the map, with their closeness to the water bodies. Given that urban and rural centers influence land-use and water bodies the presence of, we see that Villahermosa, Macuspana, Emiliano Zapata, Comacalco, and other municipalities are located near several water bodies, which can make them susceptible to flood-related risks. This type of analysis allows us to make information available that can help local communities manage water related risk. They get knowledge about the behavior of their nearest neighboring water bodies in terms of increases or decreases in their extension and storage capacity.

Sentinel missions are reducing the observation limitations of other satellite systems and strengthening the ability to monitor changes in the planet. In this case, we had a study zone, in which cloud cover is a normal condition. Therefore, this kind of zones can only be studied using radar satellite systems. The qualitative change in production and management of data from these missions is an opportunity to have spatial-temporal information that fills knowledge gaps and which will allow us develop more trustworthy models and predictions of the behavior of the Earth's ecosystems. It will also help us generate timely information for the management of flood risks, earthquakes, and other natural phenomena. The free availability of data from Sentinel satellites is the main condition to advance in a rapid way in research and in the prediction of changes in the Earth's resources and their implications for the economy and the safety of societies.

\section{Conclusion}

To monitor resources, we need to develop studies on the specific ecosystems in each region. The new technologies, such as the Sentinel missions, give us valuable information for superficial water body monitoring. The supervised classification technique was adequate, as shown 
by the results section. The procedure had very good performance (kappa $>0.9$, and overall accuracy $>90 \%$ ). This is relevant considering that it was applied to a flatland area with a dynamic hydrological regime composed of many lakes and rivers formed by rainfall and runoff. Using this technique, the seasonal changes could be detected.

This study contributes to the characterization of superficial water bodies, using short term time series, and help determine whether there are changes in their extension. It also means the beginning of the process to get to know some geographical relationships, such as the proximity of human settlements and freshwater bodies than can pose risks to the safety and economy of the communities living there. The results of this study show the potential for monitoring superficial water bodies, providing basic information for planning land and water management as well as other activities such as flood control programs. Also, an analysis of the proximity of human settlements to superficial water bodies is important for the diagnosis of socio-economic aspects that can affect safety, economy, and health, which are related to increasing poverty levels.

Superficial water body studies at the regional and local levels are increasingly important to understand processes as climate change and its effects on the Earth's surface. With short- and long-term satellite time series studies of water bodies, it will be possible to determine if there are changes related to natural variability or other changes related to man-made damages. This will allow us to develop trustworthy models and predictions of the behavior of the Earth's ecosystems that can help us develop better territorial planning processes.

\section{Acknowledgements}

This work was realized within the framework of Geo-Intelligence Laboratory (CentroGeo). Authors would also like to thank Dr. Dai Yamazaki for G3WBM information.

\section{Author details}

Alejandra A. López-Caloca ${ }^{1 *}$, Felipe Omar Tapia-Silva ${ }^{2}$ and Guadalupe Rivera ${ }^{1}$

*Address all correspondence to: alopez@centrogeo.edu.mx

1 Centro de Investigación en Geografía y Geomática “Ing. Jorge L. Tamayo” A.C. (CentroGeo), México

2 Universidad Autónoma Metropolitana Iztapalapa (UAM-I), Lab. Geomática Aplicada a Recursos Naturales, Dep. de Hidrobiología, México

\section{References}

[1] Moggridge HL, Hill MJ, Wood PJ. Urban aquatic ecosystems: The good, the bad and the ugly. Fundamental and Applied Limnology. 2014;185(1):1-6. DOI: 10.1127/fal/2014/0716 
[2] Lambin EF, Geist HJ, Lepers E. Dynamics of land-use and land-cover change in tropical regions. Annual Review of Environment and Resources. 2003;28:205-241. DOI: 10.1146/ annurev.energy.28.050302.105459

[3] Alberti M, Booth d Hill K, Avolio C, Coe S, Spirandelli D. The impact of urban patterns on aquatic ecosystems: An empirical analysis in Puget lowland sub-basins. Landscape and Urban Planning. 2007;80:345-361. DOI: 10.1016/j.landurbplan.2006.08.001

[4] Musaoglu N, Tanik A. Identification of land-cover changes through image processing and associated impacts on water reservoir conditions. Environmental Management. 2005;35(2):220-230. DOI: 10.1007/s00267-003-0270-4

[5] Steele MK, Heffernan JB. Morphological characteristics of urban water bodies: Mechanisms of change and implications for ecosystem function. Ecological Applications. 2014; 24:1070-1084. DOI: 10.1890/13-0983.1

[6] Bernhardt ES, Palmer MA. Restoring streams in an urbanizing world. Freshwater Biology. 2007;52:738-751. DOI: 10.1111/j.1365-2427.2006.01718.x

[7] Kucukmehmetoglu M, Geymen A. Measuring the spatial impacts of urbanization on the surface water resource basins in Istanbul via remote sensing. Environmental Monitoring and Assessment. 2008;142:153-169. DOI: 10.1007/s10661-007-9917-6

[8] Dunne T. Urban hydrology in the tropics: Problems, solutions, data collection, and analysis. Urban climatology and its applications with special regard to tropical areas. TR Oke, World Meteorol. Org, WMO. Mexico D.F. 1986;652:405-434

[9] Yue J. Urban rivers: A landscape ecological perspective. Hidrology Current Research. 2012;3:125. DOI: 10.4172/2157-7587.1000125

[10] Steele MK, Heffernan JB, Bettez N, et al. Convergent surface water distributions in U.S. cities. Ecosystems. 2014;17:685. DOI: 10.1007/s10021-014-9751-y

[11] Rodríguez RE. Las lagunas continentales de Tabasco. Universidad Juárez Autónoma de Tabasco. Villahermosa: Tabasco Mexico; 2012. p. 145-166 ISBN 968-7991-31-3

[12] Deng Y, Jiang W, Tang Z, Li J, Lv J, Chen Z, Jia K. Spatio-temporal change of Lake water extent in Wuhan urban agglomeration based on Landsat images from 1987 and 2015. Remote Sensing. 2017;9:270. DOI: 10.3390/rs9030270

[13] GWP Global Water Partnership. Integrated Water Resources Management. Technical Advisory Committee (TAC) Background; 2000. Paper no. 4 Stockholm, Sweden. $24 \mathrm{p}$

[14] Savenije HHG, Van der Zaag P. Integrated water resources management: Concepts and issues. Physics and Chemistry of the Earth. 2008;33:290-297. DOI: 10.1016/j.pce.2008. 02.003

[15] Guzinski R, Kass S, Huber S, Bauer-Gottwein P, Jensen IH, Naeimi V, Doubkova M, Walli A, Tottrup C. Enabling the use of earth observation data for integrated water resource management in Africa with the water observation and information system. Remote Sensing. 2014;6:7819-7839. DOI: 10.3390/rs6087819 
[16] Abell R, Thieme M, Revenga C, Bryer M, Kottelat M, Bogutskaya N, Coad B Mandrak N, Contreras-Balderas S, Bussing W, Stiassny MLJ, Skelton P, Allen GR, Unmack P, Naseka A, Sindorf RNg N, Robertson J, Armijo E, Higgins J, Heibel TJ, Wikramanayake E, Olson D, Lopez HL, REd R, Lundberg JG, Sabaj Perez MH, Petry P. Freshwater ecoregions of the world: A new map of biogeographic units for freshwater biodiversity conservation. Bioscience. 2008;58:403-414. DOI: 10.1641/B580507

[17] Atlas del Agua en México 2015. Secretaría de Medio Ambiente y Recursos Naturales y Comisión Nacional del Agua. 2015; 20-22, 56, 105 p. Printed and made in Mexico. www. conagua.gob.mx

[18] Servicio Meteorológico Nacional (SMN). Available from: http://smn.cna.gob.mx/es/ informacion-climatologica-ver-estado?estado=tab

[19] Gama L, Ortiz-Pérez MA, Moguel-Ordoñez E, Collado-Torres R, Díaz-López H, Villanueva-García C, Macías-Valadez ME. Flood risk assessment in Tabasco, Mexico. Water Resources Management. 2011;VI:631-639. DOI: 10.2495/WRM110561

[20] Freeman A. SAR calibration: An overview. IEEE Transactions on Geoscience and Remote Sensing. 1992;30(6). DOI: 10.1109/36.193786

[21] Lewis AJ. Geomorphic and hydrologic applications of active microwave remote sensing. In: Henderson FM, Lexis AJ, editors. Principles and Applications of Imaging Radar. N.Y, The United States of America: Wiley and Sons; 1998. p. 567-629 ISBN-13: 978-0471294061

[22] Brian B. Remote sensing of wetlands: Applications and advances. In: Tiner RW, Lang MW, Klemas VV, editors. In Chapter 7 in Remote Sensing of Wetlands: Applications and Advances. NY, USA: CRC Press; 2015. p. 119-136 ISBN: 978-1-4822-3735-1

[23] Manjusree P, Kumar LP, Bhatt CM, Rao GS, Bhanumurthy V. Optimization of threshold ranges for rapid flood inundation mapping by evaluating backscatter profiles of high incidence angle SAR images. Int. J. Disaster Risk Sci. 2012;3(2):113-122. DOI: 10.1007/ s13753-012-0011-5

[24] O'Grady D, Leblanc M, Gillieson D. Relationship of local incidence angle with satellite radar backscatter for different surface conditions. International Journal of Applied Earth Observation and Geoinformation. 2013;24:42-53. DOI: 10.1016/j.jag.2013.02.005

[25] Chunxi X, Jixian Z, Guoman H, Zheng Z, Jiao W. Water body information extraction from high resolution airborne synthetic aperture radar image with technique of imaging in different directions and object-oriented. Proceeding of the ISPRS Congress Silk Road for Information from Imagery, Beijing. 2008:165-168 http://www.isprs.org/proceedings/ XXXVII/congress/7_pdf/2_WG-VII-2/18.pdf

[26] O'Grady D, LeblancM, BassA. The use of radar satellite data from multipleincidence angles improves surface water mapping. Remote Sensing of Environment. 2014;140:652-664. DOI: 10.1016/j.rse.2013.10.006

[27] Bolanos S, Stiff D, Brisco B, Pietroniro A. Operational surface water detection and monitoring using radarsat 2. Remote Sensing. 2016;8:285. DOI: 10.3390/rs8040285 
[28] Brisco B, Touzi R, Van Der Sanden JJ, Charbonneau F, Pultz TJ, D’lorio M. Water resource applications with RADARSAT-2 a- preview. International Journal of Digital Earth. 2008;1(1):130-147. DOI: 10.1080/17538940701782577

[29] Brisco B, Short N, Van der Sanden JJ, Landry R, Raymond D. A semi-automated tool for surface water mapping with RADARSAT-1. Canadian Journal of Remote Sensing. 2009;35(4):336-344. DOI: doi.org/10.5589/m09-025

[30] Martinis S, Twele A. A hierarchical spatio-temporal markov model for improved flood mapping using multi-temporal X-band SAR data. Remote Sensing. 2010;2(9):2240-2258. DOI: $10.3390 /$ rs2092240

[31] Gstaiger V, Huth J, Gebhardt S, Wehrmann T, Kuenzer C. Multi-sensoral and automated derivation of inundated areas using TerraSAR-X and ENVISAT ASAR data. International Journal of Remote Sensing. 2012;33(22):7291-7304. DOI: 10.1080/01431161.2012.700421

[32] Twele A, Cao W, Plank S, Martinis S. Sentinel-1-based flood mapping: A fully automated processing chain. International Journal of Remote Sensing. 2016;37(13):2990-3004. DOI: 10.1080/01431161.2016.1192304

[33] Cazals C, Rapinel S, Frison P-L, Bonis A, Mercier G, Mallet C, Corgne S, Rudant J-P. Mapping and characterization of hydrological dynamics in a coastal marsh using high temporal resolution sentinel-1A images. Remote Sensing. 2016;8(7):570. DOI: $10.3390 / \mathrm{rs} 8070570$

[34] Muro J, Morton C, Florian R, Strauch A, Thonfeld MF, Gunter, Conradsen K, Nielsen AA, Hüttich C, Skriver H. Short-term change detection in wetlands using sentinel-1 time series. Remote Sensing. 2016;8:10-795. DOI: 10.3390/rs8100795

[35] Yésou H, Huber C, Haouet S, Lai X, Huang S, Fraipont P, Desnos Y-L. Exploiting sentinel 1 time series to monitor the largest fresh water bodies in PR China, the Poyang Lake. IEEE International Geoscience and Remote Sensing Symposium, IGARSS. 2016:38823885. DOI: $10.1109 /$ IGARSS.2016.7730008

[36] European Space Agency (ESA), Sentinel-1 User Handbook. 2013. https://sentinel.esa.int/ documents/247904/685163/Sentinel-1_User_Handbook

[37] Yamazaki D, Trigg MA, Ikeshima D. Development of a global $\sim 90 \mathrm{~m}$ water body map using multi-temporal Landsat images. Remote Sensing of Environment. 2015;171:337-351. DOI: 10.1016/j.rse.2015.10.014

[38] European Space Agency (ESA). Radiometric Calibration of S-1 Level-1 Products Generated by the S-1 IPF (Sentinel-1 Instrument Processing Facility IPF) https://sentinel. esa.int/documents/247904/685163/S1-Radiometric-Calibration-V1.0.pdf

[39] Raney RK. Radar fundamentals: Technical perspective. In: Henderson FM, Lexis AJ, editors. Principles and Applications of Imaging Radar. N.Y: Wiley and Sons; 1998. p. 31-32 ISBN-13: 978-0471294061

[40] White L, Brisco B, Pregitzer M, Tedford B, Boychuk L. RADARSAT-2 beam mode selection for surface water and flooded vegetation mapping. Canadian Journal of Remote Sensing. 2014;40:135-151. DOI: 10.1080/07038992.2014.943393 
[41] Li J, Wang S. An automatic method for mapping inland surface waterbodies with Radarsat-2 imagery. International Journal of Remote Sensing. 2015;36(5):1367-1384. DOI: 10.1080/01431161.2015.1009653

[42] Martinis S, Twele A, Voigt S. Towards operational near real-time flood detection using a split-based automatic thresholding procedure on high resolution TerraSAR- $X$ data. Natural Hazards and Earth System Sciences. 2009;9:303-314. DOI: 10.5194/ nhess-9-303-2009

[43] Andreoli R, Yésou Y, Li J, Desnos Y-L, Shifeng H, De Fraipont P. Poyang Hu (Jiangxi Province, P. R. of China) area variations between January 2004 and June 2006 using ENVISAT low and medium resolution time series. Geographic Information Sciences. 2007;13(1-2). DOI: 10.1080/10824000709480629

[44] Sabel D, Naeimi V, Greifeneder F, Wagner W. Investigating radar time series for hydrological characterisation in the lower Mekong Basin. In: Chapter 17, Remote Sensing Time Series, Volume 22 of the Series Remote Sensing and Digital Image Processing. Switzerland: Springer International Publishing. 2015;22:357-381. DOI: 10.1007/978-3-31915967-6. ISBN: 978-3-319-15966-9

[45] Kuenzer C, Guo H, Huth J, Leinenkugel P, Li X, Dech S. Flood mapping and flood dynamics of the Mekong delta: ENVISAT-ASAR-WSM based time series analyses. Remote Sensing. 2013;5(2):687-715. DOI: 10.3390/rs5020687

[46] Matgen P, Hostache R, Schumann G, Pfister L, Hoffmann L, Savenije HHG. Towards an automated SAR-based flood monitoring system: Lessons learned from two case studies. Physics and Chemistry of the Earth. 2011;36(7-8):241-252. DOI: 10.1016/j.pce.2010.12.009

[47] Martinis S, Clandillon S, Twele A, Huber C, Plank S, Maxant J, Cao W, Caspard M, May S. Improving the Extraction of Crisis Information in the Context of Flood, Landslide, and Fire Rapid Mapping Using SAR and Optical Remote Sensing Data. Vol. 18. Vienna, Austria, 17-22-04-2016: EGU 2016; 2016 EGU2016-4928

[48] López-Caloca AA, Tapia-Silva FO, Rivera G. In: Ouwehand L, editor. Living Planet Symposium, Proceedings of the Conference Held 9-13-05-2016 in Prague, Czech Republic. ESA-SP. 2016;740. p. 144. ISBN: 978-92-9221-305-3 